\title{
An empirical study to identify and rank CSFs in customer relationship management (CRM): A case study of oil products distribution
}

\author{
Mohammad Reza Zahedi $^{\mathrm{a}^{*}}$, Mohsen Cheshmberah ${ }^{\mathrm{a}}$, Seyed Mehdi Tofighi ${ }^{\mathrm{b}}$, and Ali Hadizadeh ${ }^{\mathrm{c}}$
}

${ }^{a}$ Department of Industrial Engineering, Iran University of Science \& Technology, Tehran, Iran

${ }^{b}$ Department of Industrial Engineering and System Improvement, IMD

${ }^{c}$ Department of Engineering and Management, Linkoping University Sweden

\section{A R T I C L E I N F O \\ A B S T R A C T}

Article history:

Received February 15, 2011

Received in Revised form

April, 29, 2011

Accepted 29 April 2011

Available online

30 April 2011

Keywords:

Customer

Customer relationship

management

Critical success factors

\begin{abstract}
Customer relationship management (CRM) is founded based on the value exchange between organization and customers and focuses merely on the value created in this connection. In this paper, the critical success factors are identified for a proper and effective implementation of CRM for an oil distribution company. The proposed survey of this paper identifies some important factors affecting the CRM implementation and determines the most important ones using a survey. The results indicate that there are twelve factors playing the most important roles on the success of CRM. There are CRM strategy, knowledge management in customer relationship, CRM technology, effective strategic committee, management of customer contact channels, customer information management, customer-oriented change management, training programs, strategic communication with staff, staff commitment, integration, and sectional implementation. We categorize the factors into two levels based on the level of their importance. The first level consists of the most important ones include only four items and the other eight items are categorized in level 2.
\end{abstract}

(C) 2011 Growing Science Ltd. All rights reserved.

\section{Introduction}

While economy is in the evolutionary process of globalization, the attitude of different business areas especially in providing services and interacting with customers has significantly changed. Today, enterprises are seeking to communicate individually with their valuable customers and increase their share in the market. The primary goal is to increase competition among service providers and manufacturing companies to increase the quality of services. Customer relationship management (CRM) is a set of activities to increase customer satisfaction through building a good relationship among customers, clients and sales prospects using different techniques. CRM involves using recent advances of high technology to organize, automate, and synchronize business processes such as sales activities, marketing, customer service, and technical support. In addition, during the past few years in Iran, the concepts of customer orientation and CRM have been gradually highlighted and many actions have been taken and planned by various organizations on the use of this strategy. Businesses

* Corresponding author. Tel. +98(21)77451501

E-mail addresses: Zahedy182@yahoo.com (M. R. Zahedi) 
have felt the obligation of putting customers at the center of all activities of the organization and moving from product orientation concepts to the customer orientation attitudes. Meanwhile, the national Iranian oil products distribution company (NIOPDC), as the largest distributer of oil products in Iran is not an exception in this case and the necessity of implementing CRM processes is inevitable. Especially, with regard to government policies of prioritization, NIOPDC is trying to acquire necessary capabilities to absorb the private sector. In order to achieve the organizational objectives and increase the firm's economic attractiveness in organizations with diverse clients it is necessary to attain the desired level of satisfaction among customers. This paper aims to prepare and create a framework to aid the organization to achieve CRM goals.

\section{Customer relationship management}

Increasing the information access, the power of seller has transferred to the customer and customer expectations are raised so that to meet customers' expectations in organizations, implementing CRM is an imperative job. The idea of CRM may be very simple and straightforward at one glance. With a glimpse of the available literature in this area, we realize that there are very different perceptions and interpretation of this concept. For some people, CRM is an integration of marketing tasks, sales and services by making automated business processes with the basis of information technology so that the worth of each interaction with customers could be maximized. Whereas, for some others, CRM is a business approach, which includes an integrated combination of people, strategy, process and technology so that the contact points between customers and organizations will be optimized.

Statistics reveal that many organizations are not properly informed about CRM and do not know how it should be used and who will be benefited by this new customer focus attitude. However, it should be kept in mind that the CRM alone is neither a concept nor a project. Instead, CRM is a business strategy that aims to predict, manage and customize the requirements of current and potential customers. CRM in fact, is a journey to change by which the company is searching for a better management of the organization based on the customers' behavior. This calls for the acquisition and application of knowledge regarding to customers and exploit this information in various contact points with customers in order to balance profits with the maximum customer satisfaction. The following reasons can be stated as the necessities to use CRM in an organization due to the complexity and extent of activities in each organization:

- Service improvement

- Customer satisfaction

- Reduction of customer costs

\subsection{Principal components of CRM}

Most of the theorists and researchers agree on the importance of three concepts: namely, customer satisfaction, quality service and customer loyalty and consider them as the principal components of CRM. The studies indicate that the customer satisfaction has a significant impact on keeping current customers and increasing the profitability of the company. Customer satisfaction is a key to maintain customer loyalty and superior financial performances. On the other hand, service quality is one of the areas through which organizations can achieve a competitive advantage. Service quality is defined as a universal attitude or judgment about the superiority and preference of a service and is formed by the comparison between customer expectations and their perceptions of actual service performances (Pan et al., 2006).

CRM, as a strategic process of relationship management, combines resources, knowledge, business affairs and the appropriate CRM software to provide better services based on the customer needs, their satisfaction and loyalty. The relationship between CRM and customer satisfaction is a complex issue. Increasing service quality and customer satisfactions are the promises of CRM. Therefore, 
measuring customer satisfaction will help to measure CRM capital efficiency and gives feedbacks to the whole organization by observing these quality services and products (Hart et al., 2004).

\subsection{Organizational dimensions of CRM}

In order for CRM to achieve organizational objectives, the following aspects should be considered:

- Processes: it means those processes through which the customers are related to the organization, including marketing, sales, and service.

- Strategy: it refers to the strategies that are relevant to the customer issues and specify the overall direction and goals of organizations. These strategies include mission and vision, business plan, strategic committee and short-term and long-term programs.

- Human factors (people): the key factor in CRM is how to conduct relationships with customers. Human factors play a major role in two dimensions namely organization and clients. Client dimension consists of value creation for customers, customer satisfaction and customer loyalty. Organizational dimension includes changing staff culture from product orientation toward customer orientation, creating employees' role in boosting customer satisfaction, level of participation and commitment of senior management in organization. In addition to the dimensions listed above, more general dimensions such as change management, follow up, feedback, and effective leadership should also be considered.

- Technology: it is a tool or infrastructure that facilitates the implementation of CRM. Thus, identifying technologies which are desirable for organizations based on the customer types, organizations' size, personnel properties and current systems, are essential for the company

\section{Reasons for failure of CRM projects}

According to the report of Gartner Group which is a research consulting firm, about 55\% of all customer relation management systems are not resultful. Also regarding to the research report concerning effective management tools issued by BIN Management Company in 2001 investigated the managers' level of satisfaction in applying different management practices for large companies, customer relationship management system has acquired the $23^{\text {rd }}$ rating among 25 satisfactory techniques for managers.

The common mistakes leading to failed CRM projects can be divided into two categories of strategic and operational errors.

1) Common strategic errors: includes lack of enforcement, ineffective strategic committee, lack of clear vision, poor communication, and low emissions of knowledge, poor change management, and poor training programs.

2) Common operational errors: this group of mistakes can be divided into three main groups:

1) Human errors: lack of leadership and managerial skills, poor motivation of project team staff, poor and unqualified employees.

2) Process errors: unrealistic CRM project schedule, lack of risk management practices, lack of understanding key requirements or inappropriate eliminations of these requisites, time pressure and abandoning projects, shortening or removing key activities, overdoing works, lack of an estimation of project complexity, lack of a good master plan

3) Errors in products: excessive product customization, delivery of all tasks at the same time, limited product vision.

\section{Research methodology}

This research is a descriptive survey, which uses the questionnaire in addition to library resources including books, journals, dissertations, in addition to the Persian and English articles to gather information about the literature and its statistics. The main questions of this research are as follows: 
1) What are the main components of CRM at NIOPDC?

2) What are the critical success factors of CRM at NIOPDC?

3) What is the ideal framework for implementing CRM based on CDFs at NIOPDC?

Since the present study deals with identifying the critical success factors of CRM at NIOPDC, its statistical population is the employees of the aforementioned company. In this regard, a four-part questionnaire has been designed. The first section questions about the characteristics of the respondents (descriptive indicators). The second part includes questions about each of the 18 critical success factors mentioned in Table 1 in which respondents are asked to choose any factors using which is necessary for the success of CRM implementation within the company. In the third sections, two features are questioned namely the relevance to the topic and the independency in the concept for each of the key factors. Finally, an open question is presented regarding the consideration of factors that are not already mentioned. After setting the questionnaire and running validity and reliability test, the questionnaires have been submitted and recollected through visiting directly the members of this statistical population,

\subsection{Introduction to the statistical population of the research}

The statistical population used in this study is NIOPDC staff. This selected statistical population, in addition to having the necessary background about the subject and required abilities to understand its features, has the full awareness of facilities, capabilities, and activities of organization and its strengths and weaknesses. This population includes senior and middle managers and experts at NIOPDC. In the next phase, among this statistical population in order to present the maximum coverage, 70 questionnaires have been distributed among staff including business manager, deputy director of exports and oil bunkering, deputy sale manager, president of public relations, planning manager, CNG manager, supply chain manager, and fuel smart card system manager. 50 questionnaires were answered and returned. Note that there were some regulations in governing functional structure, the financial and administrative sections of the company and the people who worked for these sections could not respond to these questionnaires, and they were excluded from the list. Table 1 demonstrates the statistical distribution of respondents according to the educational level.

Table 1

Statistical distribution of respondents based on the educational level

\begin{tabular}{lll}
\hline Percent & Frequency & Educational level \\
\hline 6 & 3 & Upper secondary education \\
38 & 19 & Bachelor \\
54 & 27 & Master \\
2 & 1 & Doctorate \\
100 & 50 & Sum \\
\hline
\end{tabular}

\subsection{Reliability and validity of questionnaires}

In order to check the validity, among different methods as content validity, criterion validity, and construct validity tests, content validity method has been used. The questionnaire is prepared by using Delphi method and finally has been approved by experts and professionals. In addition, to check the reliability of research and review the importance of each detected CSF in the area of customer relationship management, another part is listed in the questionnaire, which asks respondents to respond about the conceptual independence of each factor in comparison with other factors. This is important because the lack of conceptual independence of factors and existence of similar questions will cause a weak reliability and also responses may have a meaningful difference from one group to another. Furthermore, as the conceptual independence of one factor increases, it can be concluded that the points and the priority given to that factor, merely belongs to the same factor and is not related to other factors. Since, if two or more factors are similar, we should attempt to share points 
among them and average the total points and consider the average score for each of these similar factors. The results of this part of study has been presented in Table 2.

Table 1

Conceptual independence level of each factor compared to other factors

\begin{tabular}{llll}
\hline & Factors & $\begin{array}{l}\text { Acceptance } \\
\text { independence }\end{array}$ & rate \\
\hline 1 & CRM strategy & 77 & concept \\
2 & CRM technology & 74 \\
3 & Management of customer contact channels & 48 \\
4 & Customer information management & 57 \\
\hline 5 & Sales automation & 58 \\
6 & Knowledge management in customer relationship & 75 \\
7 & Customer orientation change management & 62 \\
8 & Customer orientation culture and attitudes & 47 \\
9 & Bright vision & 40 \\
10 & Strategic committee & 79 \\
11 & Effective leadership & 64 \\
12 & Project master plan & 41 \\
13 & Training programs & 78 \\
14 & Strategic communication with staff & 61 \\
15 & Staff commitment & 71 \\
16 & Willingness to share information & 50 \\
17 & Integration & 62 \\
18 & Sectional implementation & 56 \\
\hline
\end{tabular}

\subsection{Data analysis method}

A descriptive statistical technique is one of the simplest and at the same time one of the most transparent ways of research results representation. Accordingly, it is tried to display the research results in the simplest possible way and in the form of statistical tables and graphs. In addition, very straightforward calculations are used in preparing the reports derived from this technique,

\section{Primary identification of critical success factors in CRM}

Large scale integrated systems such as enterprise resource planning (ERP) and CRM along with their complexities, encounter many hardships and difficulties when running. Such systems have the ability to develop the organization in terms of both internal, task survey, and external, connecting with suppliers, partners and customers, and simultaneously create more efficient communications and interactions. However, there are many examples that criticize the prorogation of time and costs, defects in implementation and fewer benefits than expected in ERP and CRM application. In response to these criticisms, a number of researches propose using the critical success factors (CSF) for these systems (Mendoza et al., 2008). Steve and Pastor defined CSF as a limited number of areas in which when the results are satisfactory, it will ensure successful competitive behavior for organization (Davenport et al., 2001). In this study, it has been assumed that a factor could be considered as CSF only when its presence guarantees the successful implementation of CRM. On this basis, the key success factors related to the implementation of this project should include all aspects associated with the CRM. Different scholars have presented various cases about the critical success factors of CRM in organizations based on the case study reviews. The following factors have been selected among several credible papers according to the number of citations with the aim to study at the corresponding companies and ask experts about their importance as critical factors in CRM implementation at NIOPDC. The result is shown in Table 3. 
Table 3

Summarized critical success factors proposed by different researchers

\begin{tabular}{|c|c|c|c|}
\hline $\mathrm{CSF}$ & Mendoza et al., 2007 & Mankoff, 2008 & King \& Burgess, 2007 \\
\hline CRM strategy & & & * \\
\hline CRM technology & $*$ & $*$ & \\
\hline Management of customer contact channels & $*$ & & \\
\hline Customer information management & $*$ & & \\
\hline Sales automation & $*$ & & \\
\hline Knowledge management in customer relationship & & & $*$ \\
\hline Customer orientation change management & & & $*$ \\
\hline Customer orientation culture and attitudes & & & $*$ \\
\hline Clear vision & $*$ & $*$ & \\
\hline Strategic committee & $*$ & & \\
\hline Effective leadership & $*$ & $*$ & $*$ \\
\hline \multicolumn{4}{|l|}{ Project master plan } \\
\hline Training programs & & $*$ & \\
\hline Strategic communication with staff & $*$ & $*$ & \\
\hline Staff commitment & $*$ & & \\
\hline Willingness to share information & & & $*$ \\
\hline Integration & $*$ & & $*$ \\
\hline sectional implementation & & $*$ & \\
\hline
\end{tabular}

\section{Analysis}

The majority of the CSFs achieved the minimum level of acceptance (more than 50\%). Regarding to the selection and correct definition of the suggested critical factors, only 4 factors namely, sales automation, willingness to share information, project master plan, and clear vision did not get the desired level of acceptance. On the other hand, for CSFs that achieved the best level of acceptance (more than 80\%) more emphasis should be placed. In this research, they are called the critical factors level 1 and are as follows:

- Knowledge management in customer relationship (84\%)

- CRM strategy (82\%)

- CRM technology (80\%)

As mentioned earlier, in addition to gathering NIOPDC experts' point of view about the importance of the aforementioned success factors, we have to review each factor in terms of the conceptual independence of other factors in another part of the questionnaire. The obtained result was that most of the factors that achieved the high level of acceptance were also in high levels of communication.

Strategic committee and effective leadership were two similar features that both were preferred respectively with $68 \%$ and $60 \%$ of the votes among respondents and this indicates the importance of the project management issues by a qualified and committed leadership. This gap has been noticed by respondents very well. However, in the meantime, the strategic committee with $85 \%$ communication is placed lower than effective leadership with $95 \%$ communication. On the other hand, effective leadership with $64 \%$ conceptual independence is placed after strategic committee with $79 \%$. Thus, by considering the high percentages of these two features with $82 \%$ and $78 \%$ means, if we merge these two factors together, both will fall into the level 1 category and a common name such as the effective strategic committee can be selected for them. This is now considered as the fourth critical factor in level 1.

As seen in the table above, the priority setting for different factors is not completely based on the acceptance percentage. Although, it is clear at one glance that the level of acceptance of CSFs by respondents is one of the main features of CSF prioritization. However, some exceptions observed in this table are related to the conceptual independence and the points that are assigned to each factor. 
Table 4

Priority setting for critical success factors of CRM

\begin{tabular}{|c|c|c|c|}
\hline Level 1 & & Level 2 & \\
\hline CSF & Acceptance & CSF & Acceptance \\
\hline CRM strategy & 82 & $\begin{array}{l}\text { Management of customer contact } \\
\text { channels }\end{array}$ & 76 \\
\hline $\begin{array}{l}\text { Knowledge management in relationship with } \\
\text { customers }\end{array}$ & 84 & Customer information management & 64 \\
\hline CRM technology & 80 & $\begin{array}{l}\text { Customer orientation change } \\
\text { management }\end{array}$ & 62 \\
\hline \multirow[t]{5}{*}{ Effective strategic committee } & \multirow[t]{5}{*}{68} & Training programs & 70 \\
\hline & & Strategic communication with staff & 58 \\
\hline & & Staff commitment & 68 \\
\hline & & Integration & 56 \\
\hline & & sectional implementation & 58 \\
\hline
\end{tabular}

\section{Describing critical success factors in order of priority and impact}

\subsection{Critical factors in the first level}

These factors are very important from the respondents' point of view and have gained more than $80 \%$ of acceptance and should be addressed more deeply than other factors for the implementation of CRM at the company. These CSFs should be in first priority for the officials and project executive team.

\subsubsection{First factor: CRM Strategy}

CRM strategy in many organizations is one of the key factors of customer relationship management and has obtained a special status in this area. Strategies play an important role in determining the path and direction of the organization by unveiling of vision, goals, and the way to achieve these goals, and thus, are very important for employees in each organization. CRM strategy must be aligned with the organization's overall strategy and meet the main goals of the company and encourage and move employees towards these goals. Furthermore, this strategy should accurately determine different requirements of the organization in different aspects of CRM and appoint necessary and sufficient levels so that the company do not over-customize in CRM due to the lack of clear requirements (Greenberg, 2004).

Preparation of CRM strategy includes determining vision, goals and the utilization of the resources that are necessary for customer interaction. CRM strategy provides an attitude on how to create relationship with valuable customers and how to generate their loyalty.

For the successful implementation of CRM, management must ensure complete investigation in two areas namely "the best examples available in industry" and "the capacity of accepting CRM in the respective organization”. The important following cases are highly recommended in order to have a successful CRM strategy:

- Organization should know how the CRM strategy is coordinating with the overall organizational strategy.

- Current capacity of CRM should be evaluated and approved within the organization

- Organization must provide a reasonable business plan evidencing CRM is necessary more than any other technology for the organization.

- Preparing and implementing a good plan that will specify how the objectives can be reached. (King \& Burgess, 2007). 


\subsubsection{Second factor: Knowledge management in customer relationship}

Programs existing in the knowledge management processes organize knowledge management systems so that all basic sciences are readily available in the required fields to add value to the organization. Knowledge management offers tools, processes and facilities to employees to share knowledge based on the customer needs (Gebert et al, 2003). Employees will understand the value of the integrated knowledge about customers through knowledge management and in this way they can provide more complete services to their more valuable customers. Therefore, knowledge management serves as a means in the CRM area.

Detailed critical levels in knowledge management are as follows:

- Knowledge creation and learning: customer knowledge is a key requirement in CRM since it can be used to create "learning relationships" with customers. Customer information such as their needs and desires can be obtained through the two-way communications in an effective feedback system.

- Knowledge sharing and distribution: the value of knowledge will be increased through knowledge sharing and distribution in organization. Organizations need to create mechanisms for sharing customer knowledge to facilitate coordination efforts in different departments.

- Knowledge responsiveness: knowledge, based on the previous two cases, leads to promotion of the provided services to customers and prediction of their needs (Sin et al., 2005). Cultural aspects of employees on the willingness to share information and learning from each other are very important in knowledge management. Considering the existence of appropriate information and communication infrastructure in companies, necessary actions should be taken toward the optimal use of existing facilities to transmit needed organizational information, knowledge, experience, and technology. In this regard, necessary arrangement should be made for formal and informal notification in the company by creating a shared virtual environment and dispel weak links that exist due to the filters such as informed and illinformed prejudice, selective obedience, and delays and cunctations.

\subsubsection{Third factor: CRM technology}

CRM technology is the third factor among all factors in the first level. CRM technology includes hardware and software that lead to efficient management of interactions through customer contact points and via their back-office and front-office connections (Zablah et al., 2004).

Considering the high number of customers and the large volume of data that should be stored, the dependence of CRM to the information technology will be amplified. Collecting data in a single database allows all parts of company to share their task and information together. Having considered the lack of such technology in the organization and also the employees' responses, they have realized that the organization needs this technology to analyze customer data and purchasing patterns, process information and put the results in the employees' computers, and also study many other important factors which create the new opportunities in business (Derek, 2005).

The important issue here is to select appropriate software based on the organizations requirements and the CRM strategy. Having said that, two options are available for the organization; the first choice is to design and develop software by experts within the firm and the second choice is to purchase the software from the specialized companies outside the organization. However, careful study and selection of an expert consultant in this area is strongly needed for both cases.

\subsubsection{Fourth factor: effective strategic committee}

The effective strategic committee is the last critical success factor in level 1. Strategic committee will have impressive effects on projects and lead them to be successful by possessing competent staff. 
Strategic committee typically consists of the project and organization decision makers and gives strength to the project orientation and confirms any major operational changes that are required for the development of CRM software. The strategic committee must be along with the project and capable of quick decision making and reaching timely agreements on major operational and systematic problems.

Each problem should be shared explicitly with the strategic committee by the project manager. Main decision problems that are not shared in the right time with this committee lead projects to move in the wrong direction. Strategic committee should hold regular meetings to minimize this possibility. (Chen \& Popovich, 2003)

Strategic committee members at NIOPDC can be proposed as follows:

CEO and other important managers associated with CRM including business manager, planning manager, head of public relations, expert staff, project consultants, project manager, CRM specialist who is also good to be the project manager.

\subsection{Critical factors in the second level}

Referring to the definition provided for the first level CSFs, the following factors are those CSFs that are acceptable for less than $80 \%$ of respondents.

\subsubsection{Fifth factor: management of customer contact channels}

When customers contact the organization through various communication channels such as the World Wide Web, telephone contact center, marketing, sellers and so forth, they can receive any goods at any time, through any channel and any language that they might wish, and that's how they will feel comfortable and happy as long as they are treated as unique persons.

Now, the main points of contact with customers at NIOPDC are the face to face visit and telephone call centers. Company website and email have no major activities. Furthermore, the number of branches of the headquarter company in the region is very limited. In order to enhance the contact channels with customers, the first priority of the company must be on development of the website, managing emails and connecting them to the relevant employees and professionals. So that clients' requirement is met literally and without the need for the face to face visit.

Using advanced tools based on the browsers such as live chat sessions, instant messaging, E-learning systems, projects and web formats, audio and video playback devices, video and internet webcam, interactive sales support, and self service sales, can help company to develop in the relationship with customers.

\subsubsection{Sixth factor: Customer information management}

Data warehouse is a combination of technologies that aims to integrate effectively operational databases in the area that provides the strategic use of the data. These technologies include database management systems such as relational, multi-dimensional, server/client architecture, etc. the relationship between CRM and data warehouses will be marked with the factors such as facilities, timely access, effective and strategic use of data, and valuable information for processing and decision making in CRM which all depend on the establishment of a data warehouse. Data mining is carried out with the aim of discovering hidden relationship among data through extraction, conversion, analysis and modeling huge amounts of data in the organization database. (Curry \& Kkolou, 2004)

\subsubsection{Customer-oriented change management}


When organizations move from the traditional and product-oriented institutions to the customeroriented enterprises, they require a new infrastructure to support their own processes. Indeed, companies must change their internal structures and systems before any investment in CRM technology.

Cultural and behavioral change is an introduction to the organizational change and development. As long as the necessity of culture creation and customer-oriented attitudes is not explained and understood thoroughly through the organizational culture, other actions may not be effective. To improve the organizational culture and to support customer orientation behavior in the company, some measures can be mentioned such as boosting up the job satisfaction of employees, developing decision making culture, taking mutual responsibility, and creating reciprocal trust (Hammer \& Stanton, 1994). Organizations must eliminate their vast bureaucracy in some departments with reorganization. NIOPDC has a weak horizontal communications and a limited number of employees and managers have a clear picture of the whole organizations.

\subsubsection{Eighth factor: training programs}

There should always be adequate investment on training programs to empower the end users. Education should not be a remedy after the project accomplishment and merely focus on how to use features and functions. Rather, it should teach employees how to run the business processes that have been created by the CRM. Since the implementation of CRM will generally change business processes of the company, training should also focus on change management. If employees know how this system will make them more efficient, they will be more eager to apply that. Training schedule should be set up at an appropriate time to minimize the interval between completion of training and using the system.

\subsubsection{Ninth factor: Strategic communication with staff}

Due to the vast areas and numerous working groups involved in most of the CRM projects, understanding employees' needs and how they will be affected by communications is very imperative. Holding open meetings and direct conversations and providing feedback can minimize the negative effects of poor communications. Employees will be informed of objectives, benefits, and applications of CRM projects through educational seminars and media facilities.

\subsubsection{Tenth factor: staff commitment}

Appropriate participation of staff in all phases of the project, using their opinions in decision makings, meeting their needs, and efficient reward systems will lead to the employees' commitment to the CRM project. The more inputs of staff involved in the project is collected and combined with the function of the created product, the more attention will be devoted to the CRM project by the end users and the result will be more successful (Richards \& Jones, 2008).

\subsubsection{Eleventh factor: Integration}

Integration in two areas namely "organizational dimension" and "information system" is mandatory. The main reason for the failure of the CRM projects is the inability to integrate these projects with the old systems. Different IS systems in the organization should be linked together and information must flow among them. Thus, at operational levels it is necessary that CRM applications such as call centers, automated web-based services, etc, use the integrated data of other back-office systems as finance, human resources, etc. also from an organizational point of view, the interactions of different departments with different tasks have been increased in this way. 


\subsubsection{Twelfth factor: Sectional implementation}

Most of the successful CRM projects use a sectional plan so that each section focuses on one of the CRM goals and takes three or four month to be finished. Another advantage of applying this method is to allow learning new ideas along the way, trying these ideas with the lower risks, adding customer feedbacks to the development plans, and avoiding to repeat mistakes that you have been made at the beginning (Rigby et al., 2002).

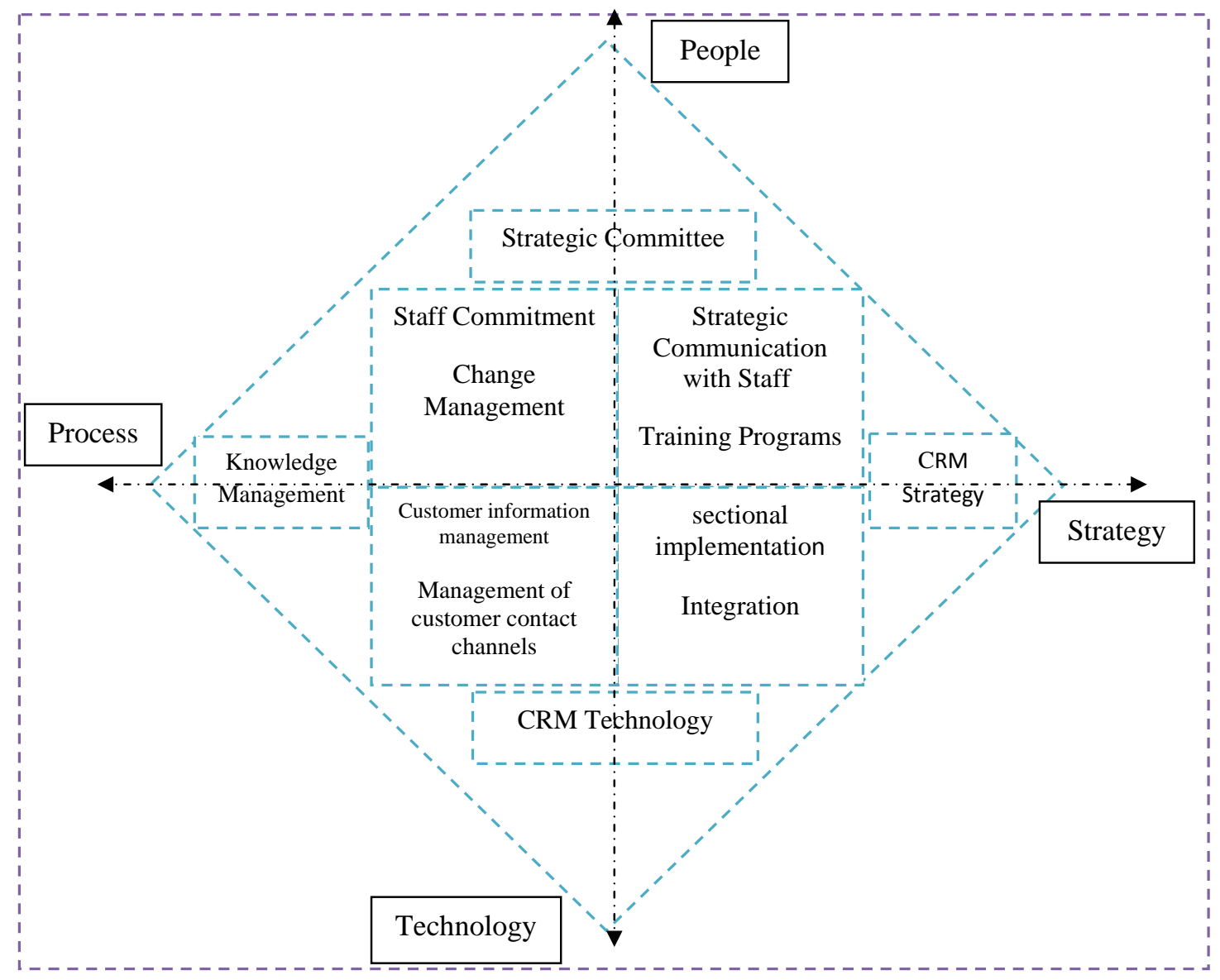

Fig. 1. Framework of CRM implementation at NIPODC

\section{Conclusion and suggestions}

In this paper, we have presented an empirical method to determine the most important factors affecting the success of CRM implementation. The proposed model has been implemented for realworld case study of oil Distribution Company and the results were divided into two levels based on their importance. The preliminary results indicate that CRM strategy, knowledge management in customer relationship, CRM technology and effective strategic committee play vital roles on the success of CRM implementation and they are considered as level one. This paper can be extended for other real-world case studies and we hope the other interested people could use the framework for their studies. 


\section{References}

Chen, I. J., \& Popovich, K. (2003). Understanding Customer relationship management: people, process and technology. Business Process Management Journal, 9(5), 672-688.

Curry, A., \& Kkolou, E. (2004). Evaluating CRM to contribute to TQM improvement- a cross-case comparison. The TQM Magazine, 16(5), 314-324.

Davenport, T.H., Harris, J.G. \& Kohli, A.K. (2001). How do they know their customers so well? MIT Sloan Management Review, 42(2), 63-73.

Derek, R. A. (2005). Customer satisfaction research management. Pearson Power.

Gebert, H., Geib, M., Kolbe, L., \& Brenner, W. (2003). Knowledge-enabled customer relationship management. Journal of Knowledge Management, 7(5), 107-123.

Greenberg, P. (2004). CRM at the speed of light. $3^{\text {rd }}$ edition. Berkeley, McGraw-Hill.

Hart, S., Hogg, G. \& Banerjee, M. (2004). The effect of experience on CRM learning. Industrial Marketing Management, 32, 549-560.

Hammer, M., \& Stanton.S.A. (1994). Reengineering work: Don’t automate obliterate. Harvard business review, 68(4), 104-112 .

King, S. F., \& Burgess, T. F. (2007). Understanding success and failure in customer relationship management. Industrial Marketing Management, 37(4), 421-431.

Mankoff, S. (2008). Ten Critical Success Factors for CRM: Lessons Learned from Successful Implementations. www.siebel.com/global/benchmark.asp.

Mendoza, L. E., Marius, A., Pérez, M. , \& Grimán, A. C. (2007). Critical success factors for a customer relationship management strategy. Information and Software Technology,49(8), 913-945.

Nguyen, T. H., Sherif, J. S., \& Newby, M. (2007). Strategies for successful CRM implementation. Information Management \& Computer Security, 15(2), 102 - 115.

Pan, S. L., Tan, C. W., \& Lim, E. T. K., (2006). Customer relationship management (CRM) in egovernment: a relational perspective Source. Decision Support Systems, 42(1), 237 - 250.

Sin, L. Y. M., Tse, A. C. B., \& Yim, F. H. K. (2005). CRM: Conceptualization and Scale Development. European Journal of Marketing, 39(11/12), 1264-1290.

Richards, K. A., \& Jones, E. (2008). Customer relationship management: Finding value drivers. Industrial Marketing Management, 37(2), 120-130.

Rigby, D. K. Reichheld, F. F., \& Schefter, P. (2002). Avoid four perils of CRM. Harvard Business Review, 80(2), 101-109.

Smith, A. (2006). CRM and customer service: strategic asset or corporate overhead. Handbook of Business Strategy, 7(1), 87-93.

Zablah, A. R., Bellenger, D. N., \& Johnston, W. J. (2004). An evaluation of divergent perspectives on customer relationship management: Towards a common understanding of an emerging phenomenon. Industrial Marketing Management, 33(6), 475- 489. 